\title{
BIM FOR MUSEUMS: AN INTEGRATED APPROACH FROM THE BUILDING TO THE COLLECTIONS
}

\author{
G. Tucci ${ }^{1}$, M. Betti ${ }^{1}$, A. Conti ${ }^{1, *}$, M. Corongiu ${ }^{1}$, L. Fiorini ${ }^{1}$, C. Matta ${ }^{2}$,V. C. Kovačević ${ }^{1}$, C. Borri ${ }^{1}$, C. Hollberg ${ }^{2}$ \\ ${ }^{1}$ Dept. of Civil and Environmental Engineering, University of Florence, via Santa Marta 3, Firenze, Italy \\ grazia.tucci@unifi.it,mbetti@dicea.unifi.it,arch.a.conti@gmail.com, lidia.fiorini@gmail.com, manuela.corongiu@unifi.it, \\ vladimir.kovacevic@kobe-ie.com, claudio.borri@unifi.it \\ ${ }^{2}$ Galleria dell'Accademia di Firenze, Ministero per i Beni e le attività Culturali, Via Ricasoli 58-60, Firenze, Italy \\ carlotta.matta@beniculturali.it, cecilie.hollberg@beniculturali.it
}

KEY WORDS: HBIM, Seismic Risk Assessment, FEM, museum collections, preventive conservation

\begin{abstract}
:
The paper discusses the first outcomes of an ongoing research activity aimed at developing a general BIM-based methodology for the organization and the management of the information needed for maintenance and safety assessment of museums. The Galleria dell'Accademia di Firenze (Florence, Italy) which has a very complex spatial organisation as a result of transformations occurred over the centuries, has been considered as an illustrative application of the proposed methodology. One of the specific elements which characterize museums, compared to other buildings, is the issue of the relationship between the building itself and the artworks there contained. A specific element of the research is consequently the need not to limit the attention to only the building (i.e. the envelope), but to consider within the BIM also the presence of the art collections. Starting from a recent laser scanner survey, a BIM has been created and a semi-automatic workflow has been investigated to obtain a FE (Finite Element) model to be employed for static and dynamic structural analysis purposes. Currently, since the scans inevitably included the artworks, a test is underway to add in the BIM of the museum also its collections (M-BIM). Each element can be inserted as a BIM object including its geometric representation and physical data (dimensions, materials, weight...) and linked to different museum inventory and conservation databases for the museum management.
\end{abstract}

\section{INTRODUCTION}

The origins of the Galleria dell'Accademia di Firenze (Florence, Italy) date back to the eighteenth century, when Grand Duke Pietro Leopoldo gathered in the premises of the ancient Ospedale di San Matteo and the convent of San Nicola di Cafaggio a modern Academy of Fine Arts along with other schools and art workshops in the city. The most significant transformation took place in 1783 when a new building (the "Tribuna"), designed by the Italian architect De Fabris, was explicitly built inside the complex for the relocation of Michelangelo's David from Piazza della Signoria.

The Gallery occupies a large part of an urban block that it shares with the most prestigious institutions for arts education and restoration in Florence: the classrooms, auditorium and libraries of the Accademia di Belle Arti and the Conservatorio Musicale Cherubini, the laboratories and museum of the Opificio delle Pietre Dure. It is a building complex whose structural behaviour is strongly characterised by the interaction between its many parts. The different buildings of the complex are articulated in an intricated spatial organisation, as a result of transformations occurred over the centuries without any unitary project. This lack of unity makes it difficult to read the spatial and functional subdivision of the different parts of the Galleria. Also, for this reason, such a famous museum, the fourth in Italy for the number of visitors (over a million and a half in 2017), suffers from a chronic scarcity of space. The museum, for example, lacks many of the services usually available in such prestigious museums as the coatroom or the cafeteria and even the administrative offices are insufficient. For example, the deposit consists of only one small room, a modest space at the first floor, carved out of the museum route by a glass frame, so even for minor maintenance works an alternative location of the artworks must be studied.

Finally, although there are many important collections, including the world's richest collection of gold background ancient paintings, a prestigious collection of musical instruments and six other sculptures by (or attributed to) Michelangelo (the "Prisoners", St. Matthew and the Palestrina Pietà), the exhibition must take into account that visitors visit the museum almost exclusively to see the Michelangelo's David. In short, as with nearly all Italian museums, priceless works of art are kept in a historic building designed following criteria very different from the current ones, particularly about the pressure of mass tourism and the risks (first and foremost the seismic one) to which the building and the artworks are subjected. A different distribution of space between the Galleria and the neighbouring institutions (Accademia di Belle Arti, Conservatorio Musicale Cherubini and Opificio delle Pietre Dure) is currently under esamination.

The paper presents the activities underway for the creation of an information management system for the Galleria dell'Accademia di Firenze including both information on the building and the collections as a tool for managing this complex activity, formulating hypotheses, making simulations and decisionmaking. The research considers two complementary aspects; the first deepens the investigation started in 2010 regarding seismic risk assessment, the second one concerns the possible inclusion in BIM of information related to the art collections.

\footnotetext{
* Corresponding author
} 


\section{STATE-OF-THE-ART}

The creation of information management systems for the built environment in a spatial form using BIM or GIS systems is one of the main issues of contemporary research and therefore the bibliography on it is very extensive. Building Information Modelling is the new paradigm of digital design and management and its use is already mandatory in some countries, so it is applied for the design of all kind of buildings including, of course, new museums. In combination with Geomatics techniques for 3D data acquisition, it is also increasingly applied for the documentation and management of historical buildings (HBIM, see Lopez et al., 2018 and Pocobelli et al., 2018). In this case, its use is still episodic, also because, unlike new constructions, their material and constructive consistency must be largely reconstructed only knowing their exterior characteristics. However, it's evident the advantage that can derive from collecting all the information on a building in a single database, which can be gradually integrated with further investigations, especially for the large complexes whose knowledge is usually divided between many specialists.

Given the challenge of applying a methodology designed for new buildings to existing ones, the focus of the research was mainly on the problem of the representation of forms and irregularities of historical architecture. For the realisation of a BIM model of an existing building surveyed with geomatic techniques (As-found BIM), there are different approaches (Barki et al., 2015). A possible method is to adapt the components available in the BIM software (walls, floors, etc.) to an existing 2D CAD drawing (CAD-to-BIM) or to construct simplified parametric geometries (Capone et al., 2019). When point clouds from a survey performed with geomatic techniques are available, whose use is not natively included among the modelling tools of the BIM software, different workflows (Scan-to-BIM) have been proposed for attempting to extract automatically or semi-automatically the desired features (Wang et al., 2019), in particular for modelling the irregular geometry of historical buildings. Many BIM software can display point clouds for visual reference (Macher et al., 2017), other workflows involve the importation of mesh (Yang et al. 2018) or NURBS geometries (Brumana et al., 2018 and Korumaz et al. 2017) generated in other software.

A smaller number of studies concern the use of BIM models of existing and historical buildings, in particular for building conservation and management activities (Joblot et al., 2017; Bitelli et al., 2017; Bruno et al., 2018; Rodrigues et al., 2019). Most of them concern their use for structural analysis and in particular for the realisation of FE models (BIM-to-FEM, Dore et al., 2015; Barazzetti et al., 2015), others examine the issue of energy retrofitting of historical buildings (Khodeir et al., 2016; Gigliarelli et al., 2017). While the digitisation of museum objects is a well-known topic, especially for making models for the web or the creation of virtual museums, as far as we know, no previous research has investigated the use of BIM for the integrated management of the museum building and the collections. A recent study (Turco et al., 2019) is focused on the creation of semantically enriched 3D models (called Collection Information Models - CIM) and mentions the possibility to operate on the system of relationships between objects (contents) and museum (container) within the BIM environment.

\section{GEOMETRIC SURVEY AND MODELLING}

The experience of the Galleria dell'Accademia di Firenze, whose architecture almost has all the existing issues related to the analysis of historic structures, continues a research began in 2010, when the Direzione Regionale per i Beni Culturali e Paesaggistici della Toscana tested in the museum the application of the "Guidelines for Seismic Risk Assessment and Reduction of Cultural Heritage". On that occasion, an accurate laser scanner survey was carried out obtaining complete 2D architectural and structural CAD drawings of the building (Tucci et al., 2017).

Already in the previous step, the aim of carrying out a structural survey required the detailed positioning of all vertical and horizontal structural elements and to verify the nature and thickness of the structures, and it was also necessary to extend the survey to the portions of the neighbouring buildings that share vertical walls and floors with the museum. This was useful, on the one hand, for an in-depth study of the structural model, and on the other hand, it allows now to design different distribution solutions for the spaces of the Galleria.

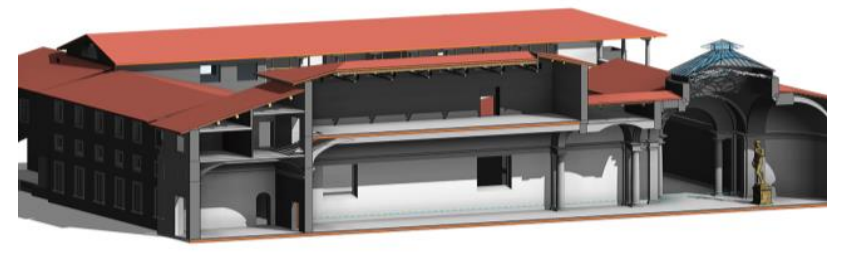

Figure 1. Cross section of the Building Information Model.

The first topic of the new research had the aim of creating a BIM model for the implementation of a FE model and therefore has mainly concerned the elements that should be represented in the structural model (Figure 1). The modelling was performed using different approaches. The availability of CAD drawings of the previous survey led to performing in most cases a CAD-toBIM modelling using the parametric modelling tools available in the Autodesk Revit ${ }^{\circledR}$ software. In general, this workflow is considered inefficient because i) it requires an intermediate step, ii) the survey may not be accurate or up to date, iii) there may be vectorisation errors. In this case, however, it was a survey recently carried out by the same working group and whose reliability was therefore well known.

For the modelling of elements not represented in 2D drawings, the point cloud has been imported and used as a visual reference for the 3D modelling. Finally, in the case of structures whose deformation was already known, In-place components created from surfaces modelled in other software were used. In particular, different approaches were used for modelling the vaults: for serial elements with similar geometry and characteristics, parametric models were prepared tailored to the size of the individual instances, for single vaults In-place elements were modelled according to the profiles and paths present in the 2D survey or extracted from the point cloud. In the area of the "Tribuna", the 2D drawings highlighted different dimensions of the arcs at the end of the concurrent part of the building: the 3D model cleared that this expedient made it possible to obtain a perfectly regular drum for supporting the large skylight.

The current model is an initial step in the implementation of a fully operational BIM. Currently, the model essentially contains the geometric and semantic information on the load-bearing structures, to be integrated with data on the finishes and characterisation of the materials. In the previous phase of the study, tests and trials had already been carried out in many areas, but they were not able to clarify all the aspects concerning the discontinuity of the masonry and its 
connections. After all, one of the opportunities of BIM is that it is always possible to enrich models with additional data and to add other information by creating links to external databases. Also, what level of detail (LoD) or level of development is the most appropriate for the various applications is still a controversial issue. Often, however, the geometric and semantic information of a model must be purposely processed to be used in specific applications, for example for structural or energy analysis, (Díaz Vilariño et al., 2017).

\section{STRUCTURAL ANALYSIS PROCEDURE}

\subsection{FE Modelling}

The Finite Element (FE) technique is today amongst the most diffused methods used to assess the structural behaviour in the general Computational Mechanics context and especially in the field of Civil Engineering Applications (Pepper et al., 2014). Particularly relevant, in recent years, for academic and research application projects is the open source salome_meca environment: a platform which includes the FE solver code_aster, developed since the late ' 80 s by EDF (Elecricité de France) and diffused under LGPL license since the beginning of the 2000s (Pieraccini et al., 2017 and Bartoli et al., 2017).

Two main inputs are needed to build reliably and consistently a FE Model: i) the mesh and ii) the additional information to be implemented within the finite elements (properties, loads, boundary conditions etc.). The mesh can be obtained from a geometrical input of topological content, such as a combination of primitive forms, or producing this content directly from other sources, such as terrestrial laser scanning (TLS), based on cloud points outputs (Bitelli et al., 2016; Castellazzi et al., 2017; Korumaz et al., 2017). The former procedure is more compatible inside a BIM or H-BIM context, where the availability of data, or data storing procedures, can help in improving the interoperability and easily retrieving information from the same databases. This results in the possibility to obtain both the geometry and the information needed to build the FE Model (Barazzetti et al., 2015).

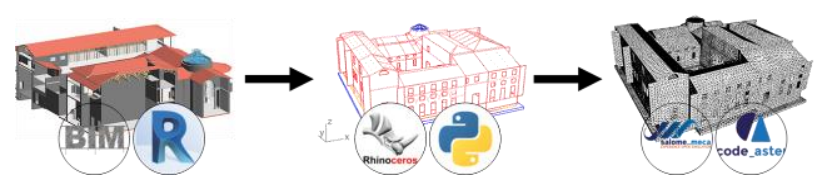

Figure 2. Transformation of the model in the BIM, geometric and FEM environment.

Actually, the salome_meca platform provides the possibility to handle complex geometrical inputs from external sources, such as neutral format files (BREP, STEP, IGES, STL etc.), and consequently generate a FE compatible mesh as the starting geometry for the model. Information on the model properties can also be loaded from external sources and implemented in the analysis command script or directly on the geometry (for instance the identification of coherent geometrical groups). All the three steps (1- geometry importing and manipulation, 2mesh generation and 3- the analysis command file creation; Figure 2) can be wrapped in Python compatible language and employed to build a full-run FE analysis.

A sufficiently flexible environment - Rhinoceros ${ }^{\circledR}$ - was chosen to build the geometry and define the objects dedicated to structural purposes, starting from the original BIM container, a Revit $^{\circledR}$ model in this case, ideally common for all purposes (architectural, structural, management of the exhibitions or collections, etc.). The choice was guided by i) the need for the implementation of complex and non-regular shapes, such as structural vaults, out-of-plane deformed walls, ii) the need to simplify the structural elements representation (1D frames and 2D shell elements instead a fully 3D model), which results in an object-oriented programming approach, iii) the possibility to build additional or modify existing complex geometrical entities, iv) the possibility to manage internal or external databases. This is mainly possible in the Rhinoceros ${ }^{\circledR}$ environment thanks to the Python programming language-based interface, which is a link with the salome_meca platform.

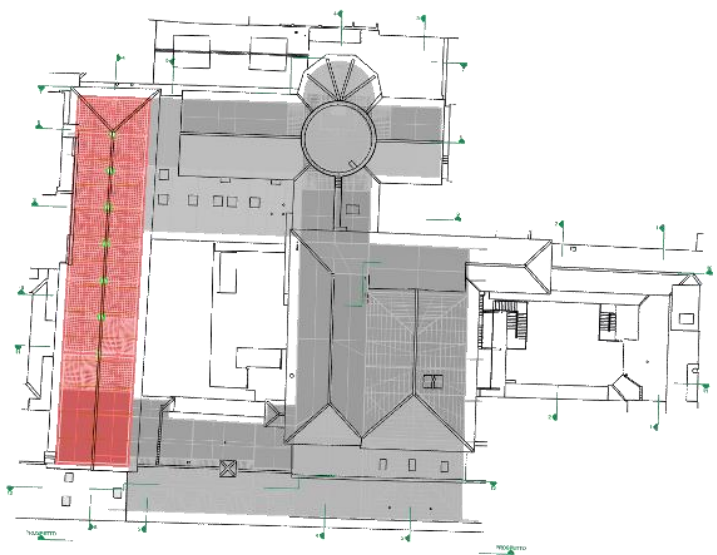

Figure 3. Superposition of the 3D FEM geometry in Rhinoceros ${ }^{\circledR}$ with the 2D drawing layer.

With the proposed workflow, summarized in Figure 2, it was possible to:

- manage the geometry of the object to be built with the Rhino modeler and ideally de-rived from the external BIM model (Figure 3);

- add information on the geometrical structural objects and ideally derive it from the BIM database;

- export the enriched geometry in a salome_meca compatible form;

- import the enriched geometry in the salome_meca environment (Figure 4);

- build the computational finite element model and run the analysis (Figure 4).

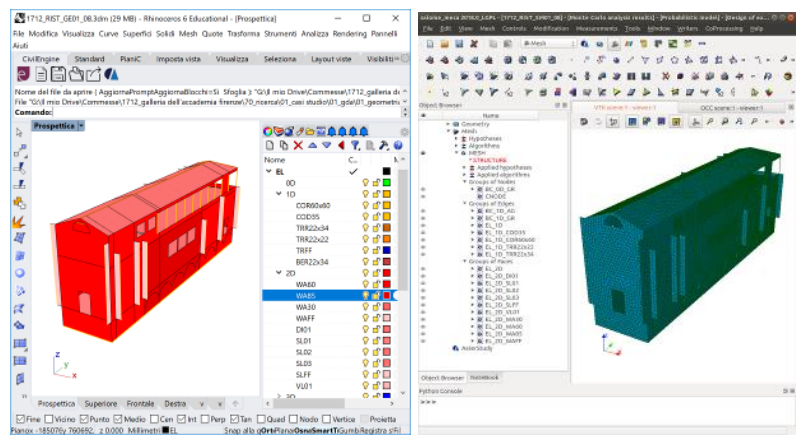

Figure 4. Geometry and FEM mesh environment.

Next steps will involve the direct integration of the BIM model management (i.e. with the aid of Rhinoceros plug-ins such as VisualARQ, which maintains the original environment flexibility), or even the possibility to directly import IFC 
standard format files through the identifications of structural objects inside it.

\subsection{Assessment of the dynamic behaviour}

The dynamic behaviour of structures can be estimated by performing the linear modal dynamic analysis as a first order approach. The sparsity of the modal shapes, or a high number of the modal shapes needed to obtain an acceptable cumulated mass participation factor, is an index which shows the main presence of local rather than global effects: this is particularly true for masonry and complex historical structures, with flexible diaphragms and in an aggregate built context (Betti et al., 2014; Greco et al., 2018).

As a first step of the ongoing research, the investigation has been focused on a portion of the museum, which is the unit called "Sala dei Gessi" (Figure 5): an extended rectangular building, confined by the Accademia di Belle Arti on the western side and by the "Tribuna" and the Accademia Bibliotheque of the on the NE and SE side. A global and local poor seismic performance was assessed for this building by previous studies, considered as an isolated object (De Stefano et al., 2018).

A parametric modal analysis was carried out to assess the behaviour of the first mode shapes of the unit "Sala dei Gessi" in an aggregate building hypothesis, where the local vertical restraints has been represented by a stiffness parameter (Tab. 1).

\begin{tabular}{|c|c|c|c|}
\hline N. & $\begin{array}{c}\text { E_wf }= \\
\text { 0 }\end{array}$ & $\begin{array}{c}\text { E_wf }= \\
\mathbf{2 0 0}\end{array}$ & $\begin{array}{c}\text { E_wf }= \\
\mathbf{1 0}^{\mathbf{6}}\end{array}$ \\
\hline 1 & $\mathbf{1 . 5 5 7}$ & $\mathbf{3 . 5 4 1}$ & $\mathbf{3 . 9 7 1}$ \\
2 & $\mathbf{2 . 4 6 5}$ & $\mathbf{3 . 9 5 9}$ & $\mathbf{4 . 8 8 4}$ \\
3 & 3.055 & 4.083 & 4.983 \\
4 & 3.779 & 4.669 & 5.710 \\
5 & 3.946 & 4.712 & 6.022 \\
6 & 4.021 & 5.121 & 6.502 \\
7 & 4.332 & 5.269 & 6.635 \\
8 & 4.678 & 5.606 & 6.955 \\
9 & 4.866 & 5.806 & 7.277 \\
10 & 5.271 & 6.202 & 7.369 \\
11 & 5.349 & 6.342 & 7.524 \\
12 & 5.656 & 6.482 & 7.824 \\
13 & 6.001 & 6.927 & 7.840 \\
14 & 6.315 & 7.120 & 8.035 \\
15 & 6.414 & 7.178 & 8.044 \\
\hline
\end{tabular}

Table 1. Vibrating frequencies of the first 16 modal shapes of the "Sala dei Gessi", with different in-aggregate restraint conditions (from isolated to fully constrained).

This brought to evidence the local nature of the majority of the mode shapes (Figure 6), caused both by the irregular conformation of some structural parts and by the in-aggregate variable restraint conditions. The frequency variability is the main parameter that will influence the acceleration acting on the building parts during a seismic event.

Finally, the parametric study was sampled, and it was possible to build a distribution of the frequency output distribution (Figure 7), based also on a first assessment of the input parameters, such as the material mechanical properties, derived from existing vulnerability assessment guidelines (CNR, 2014).

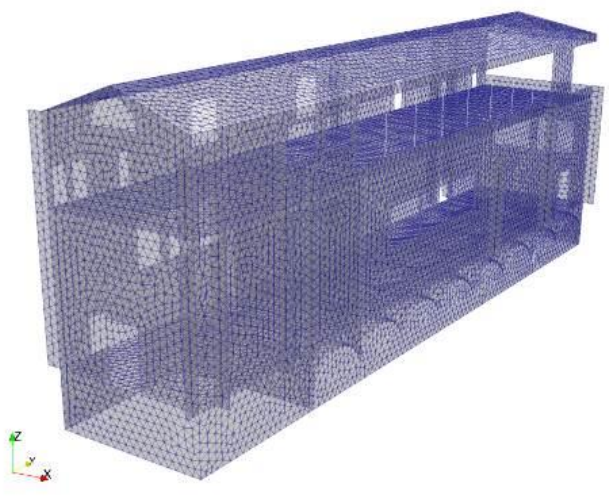

Figure 5. The mesh created for the finite element model of the "Sala dei Gessi".
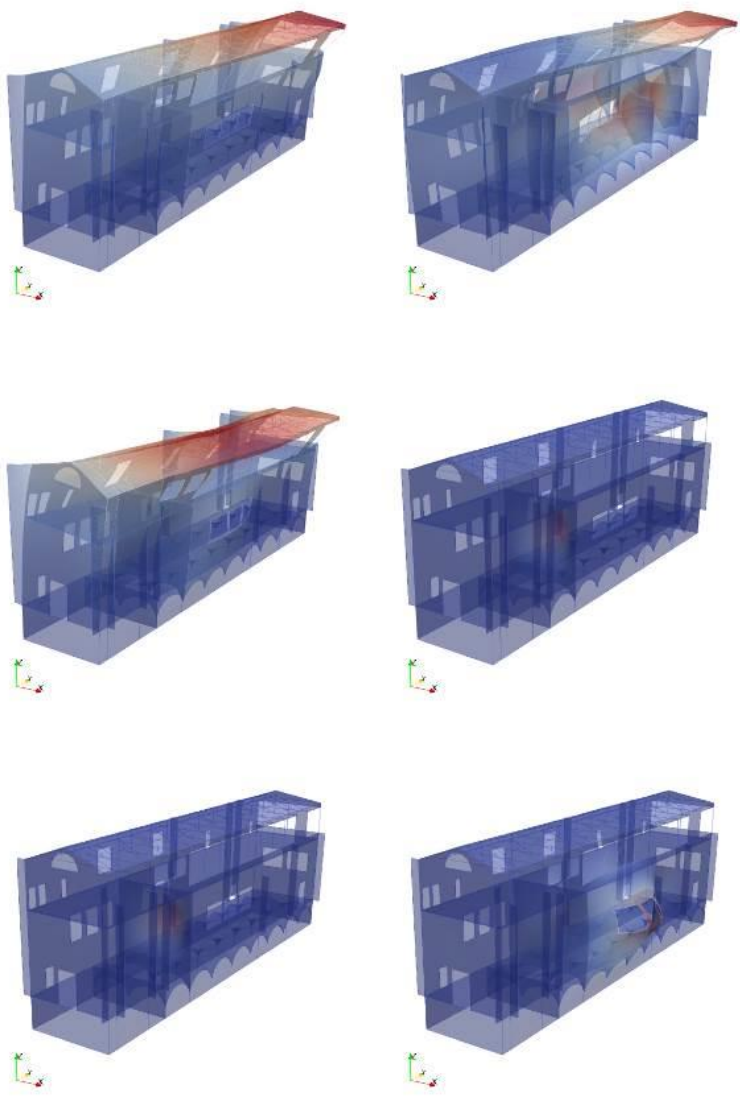

Figure 6. First 2 modal shapes for different in aggregate restraint conditions (from isolated to fully constrained).

The workflow here presented aims to build an standardized procedure in order to i) chain the construction of a numerical or simulation model derived from TLS survey data and interpreted by BIM procedures and ii) use this model to quickly assess the static and dynamic behaviour of the structure. This procedure could be exploited not only for the evaluation of the structural elements' behaviour inside a museum complex, but also to assess the safety of the artworks which populate it. Global and local failure types could then complete the overall assessment of the building and its precious content. 


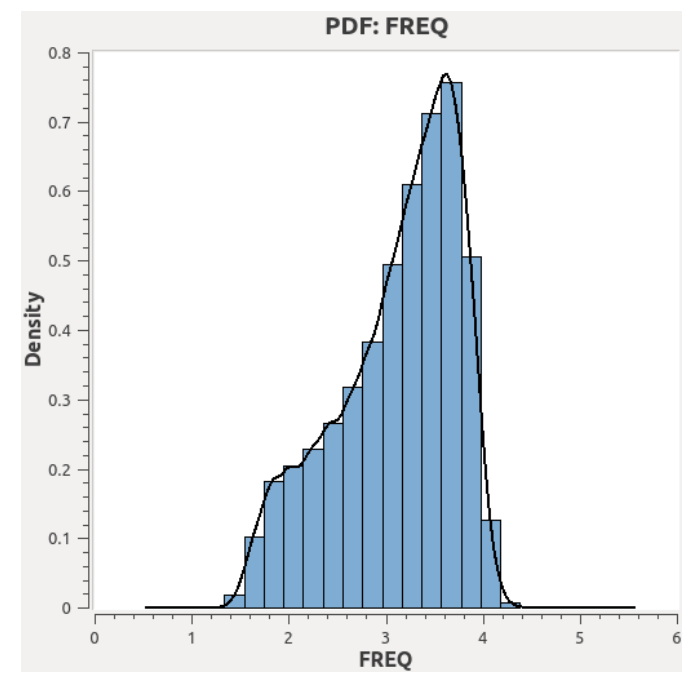

Figure 7. Frequency output distribution.

\section{M-BIM: A BUILDING INFORMATION MODEL FOR MUSEUM MANAGEMENT}

\subsection{The (Confidential) Facility Report}

The usefulness of developing an information management system encompassing both the museum building and the related collections (Museum BIM or M-BIM) stems from many considerations. The Italian norm "Guidelines for the assessment and mitigation of seismic risk of cultural heritage buildings" (MIBAC, 2008) indicates for historical buildings a "limit state of damage to artistic heritage" (SLA) that concerns the damage to decorations that can be significant even if no major structural damage is involved (Tucci et al., 2018). In the case of a museum, mainly if it is contained in a historical building, the artworks are therefore closely linked to the destiny of the building in which they are located and they must be protected against disasters (ICOM, 2017). Moreover, all the museum's management activities, whether related to the management and maintenance of the building or the study, conservation, use and promotion of the collections, are connected to their physical and location characteristics according to the principle of preventive conservation.

International best practices, in particular with regard to the loan of art works, require the drafting of documents describing the characteristics of a piece (conservation report, see Green and Mustaligh, 2009) and those of the property in which they will be exhibited (facility report, see AAM-RC, 1998; UKRG, 2015). The latter contains all the information needed to assess the physical, environmental, management, security and safety characteristics of a museum and therefore the risks to which a loaned work may be vulnerable.

In Italy, the issue of preventive conservation of Museums was initially examined by the (D.M. 10/5/2001) which sets out criteria for the definition of standard quality levels. In particular, section III concerns the museum structures and proposes the definition of accreditation procedures according to international best practices, while section VI regards the management of the collections, indicating the need to draw up conservation reports of the works and technical data sheets regarding the environmental and microclimatic conditions.

In 2018 this led in 2018 to the adoption of minimum quality levels for museums (D.M. 113/2018) which set minimum standards and improvement targets for all aspects of museum management, including building structures and collections.
The requirements of the building to be examined concern:

- the comfort of exhibition spaces;

- access for people with disabilities;

- safety (indicating compliance with regulations on structural engineering, MEP, sanitation, accessibility and so on);

- while the items listed regarding the collections are:

- periodic monitoring of the state of conservation of the collections;

- formalised procedures for the management and control of handling operations;

- new acquisitions;

- registration, documentation and cataloguing of the collections

- permanent exhibitions;

- temporary exhibitions;

- R\&D programmes and activities;

- organisation of deposits

At regional level, a significant contribution came from (D.G.R. 29/05/2012 n. 24-3914) which introduced the methodology called Confidential Facility Report (Filippi et al., 2010) in which drawings, charts and images are used to describe structures, security measures, technical systems, etc., with particular attention to the control of microclimate and environmental parameters (relative humidity, temperature, lighting and air quality).

Many studies concern the microclimatic control of Museums and their collections (see Lucchi, 2018), using in some cases BIM (Bonora et al., 2018).

It is evident that much of the technical information required for the drafting of the above-mentioned documents or useful for planning the necessary interventions to achieve the missing objectives is contained or can be managed with BIM.

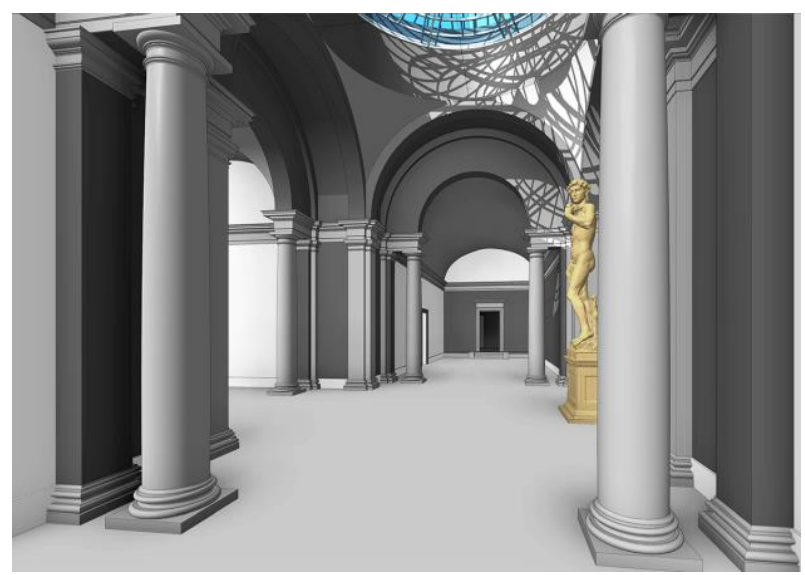

Figure 8. Michelangelo's David in BIM.

\subsection{Including artworks in BIM}

The use of BIM to manipulate and manage the collections of the Galleria dell'Accademia di Firenze is currently under experimentation, involving the insertion of models of individual items in BIM (Figure 8). In Autodesk Revit ${ }^{\circledR}$ it is possible to create objects from imported meshes but, for good operability, they must have a low resolution. The tests were carried out using models obtained from the scans completed in 2011 for the survey of the building, except for the ones performed for documenting the restoration of the model of the "Ratto delle Sabine" (Tucci et al., 2016). In such cases, when the assets consist of medium-large objects, also point clouds obtained with mobile mapping techniques while surveying the building could be used (Masiero et al., 2018). In other instances, 3D 
models already produced for the many cultural heritage digitisation initiatives could be used, although they should be drastically decimated. In general, low resolution models are sufficient for the experimentation carried out, as long as the single objects can be distinguished and their size and main dimensional parameters can be evaluated.

In the test, the works of art were imported using the Autodesk Revit ${ }^{\circledR}$ "furniture" family (Figure 9), but an appropriate family can be created with specific fields for the connection to one or more external databases, ranging from the historical databases of the former Polo Museale Fiorentino to other kinds of inventory registers, conservation reports, cataloguing data sheets according to national and international standards (CIDOC-CRM, Dublin Core...). Other fields to be entered could include for example the weight of the objects (directly measured or estimated), wall hanging systems, images, web links, specific conservation needs, handling requirements, etc. The test involved the insertion of the fields and the image found in the inventory sheet and allowed the automatic updating of the connected data (Figure 10).

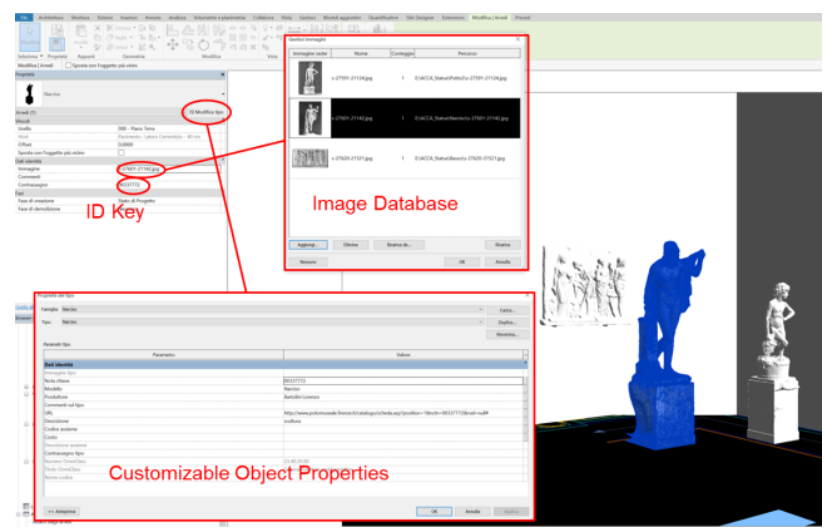

Figure 9. Artworks properties management test.

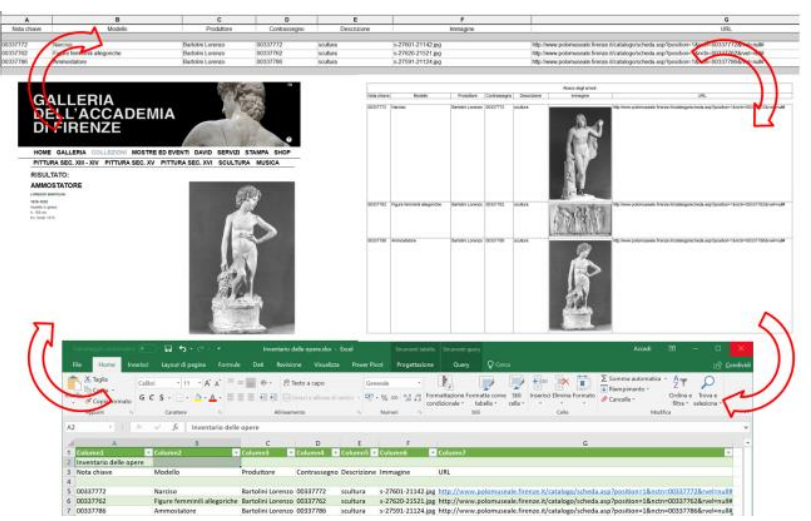

Figure 10. Data exchange between BIM schedules/quantities, external software and web inventory.

This enables the insertion of the collection's items in the building model and their management using the tools provided in the BIM software or in other software that can handle data in IFC format, for example for:

- making drawings, reports and tables according to the preferred criteria;

- recording the evolution of the installations of the museum;

- doing structural analyses that take into account also the cultural assets;
- designing new displays, temporary exhibitions or lighting design;

- studying the handling of the art works;

- calculating the loads on the floors and walls;

- verifying the compatibility between the location of a piece and its microclimatic conditions;

- managing the cleaning and maintenance of the works.

In addition to these applications for museum management, there are other applications for communication and museum users, such as virtual or augmented reality applications that can take advantage of the presence of 3D models of works of art in the context of the building model (Masiero et al., 2019).

\section{CONCLUSIONS AND FUTURE WORK}

Within the framework of the creation of spatial information systems for historical buildings, one of the most active topics of contemporary research on built cultural heritage, the paper examined the specificity of the creation of a BIM model for historic museum such as the Galleria dell'Accademia di Firenze. The paper also considers the opportunity of developing information management systems for Museums (M-BIM) including both the building and collections data. Future research should be devoted to i) the enrichment of the geometric and semantic information of the model (especially about MEP components), ii) the integration with the data collected by the environmental monitoring network existing in the museum, iii) the interoperability of data collected in the art works inventory registers in BIM environment. In this way, all the information useful for the planned conservation and management of the museum can be integrated into an overall model and managed with BIM tools.

The presented and discussed workflow aims to set-up an effective procedure in order to link the construction of a numerical model from TLS survey data and interpreted by BIM procedures. This procedure could be exploited not only for the evaluation of the behaviour of the structural elements inside a museum complex, but also to assess the safety of the artworks inside.

\section{REFERENCES}

AAM-RC 1998. Registrars Committee of the American Association of Museums. Standard Facility Report adopted $1998 . \quad$ Online: http://sceti.library.upenn.edu/dreyfus/docs/Standard_Facility_R eport.pdf (10 March 2019).

Barazzetti, L., Banfi, F., Brumana, R., Gusmeroli, G., Previtali, M., \& Schiantarelli, G. 2015. Cloud-to-BIM-to-FEM: Structural simulation with accurate historic BIM from laser scans. Simulation Modelling Practice and Theory, 57, 71-87. doi.org/10.1016/j.simpat.2015.06.004.

Barki, H., Fadli, F., Shaat, A., Boguslawski, P., Mahdjoubi, L. 2015. BIM Models Generation from 2D CAD Drawings and 3D Scans: an Analysis of Challenges and Opportunities for AEC Practitioners. In: Building Information Modelling (BIM) in Design Construction and Operations. WIT Press. doi: 10.2495/bim150311.

Bartoli, G., Betti, M., Biagini, P., Borghini, A., Ciavattone, A., Girardi, M., Lancioni, G., Marra, A.M., Ortolani, B., Pintucchi, B. 2017. Epistemic uncertainties in structural modelling: a blind benchmark for seismic assessment of slender masonry towers. ASCE's Journal of Performance of Constructed Facilities; 

31(5), 04017067. doi.org/10.1061/(ASCE)CF.1943-
5509.0001049.

Betti, M., Galano, L., Vignoli, A. 2014. Comparative analysis on the seismic behaviour of unreinforced masonry buildings with flexible diaphragms. Engineering Structures, 61, 195-208. doi.org/10.1016/j.engstruct.2013.12.038.

Bitelli, G.; Balletti, C.; Brumana, R.; Barazzetti, L.; D’Urso, M.G.; Rinaudo, F.; Tucci, G. 2017. Metric documentation of cultural heritage research directions from the Italian GAMHer project. Int. Arch. Photogramm. Remote Sens. Spatial Inf. Sci., XLII-2/W5, 83-90 doi.org/10.5194/isprs-archives-XLII-2-W583-2017.

Bitelli, G., Castellazzi, G., D’Altri, A.M., De Miranda, S., Lambertini, A., Selvaggi I. 2016. Automated voxel model from point clouds for structural analysis of cultural heritage. Int. Arch. Photogramm. Remote Sens. Spatial Inf. Sci., XLI-B5, 191-197. doi.org/10.5194/isprs-archives-XLI-B5-191-2016.

Bonora, A., Fabbri, K., Pretelli, M. 2018. Study of the indoor microclimate for preventive conservation and sustainable management of historic buildings. The case of Villa Barbaro, Maser. In: Energy Efficiency in Historic Buildings Tor Broström T. et al. eds, Uppsala University, Department of Art History, 381-390 ISBN: 978-91-519-0838-0.

Brumana, R., Della Torre, S., Previtali, M., Barazzetti, L., Cantini, L., Oreni, D., Banfi, F. 2018. Generative HBIM modelling to embody complexity (LOD, LOG, LOA, LOI): surveying, preservation, site intervention-the Basilica di Collemaggio (L'Aquila). Applied Geomatics, 10(4), 545-567. doi.org/10.1007/s12518-018-0233-3.

Bruno, S., De Fino, M., Fatiguso, F. 2018. Historic Building Information Modelling: performance assessment for diagnosisaided information modelling and management. Automation in Construction, 86, 256-276.

doi.org/10.1016/j.autcon.2017.11.009.

Capone, M., Lanzara, E., 2019. Scan-To vs 3d Ideal Model HBIM: Parametric Tools to Study Domes Geometry, Int. Arch. Photogramm. Remote Sens. Spatial Inf. Sci., XLII-2/W9, 219226. doi.org/10.5194/isprs-archives-XLII-2-W9-219-2019.

Castellazzi G., D’Altri A. M., de Miranda S., Ubertini F. 2017. An innovative numerical modeling strategy for the structural analysis of historical monumental buildings, Engineering Structures, 132(1) 229-248.

doi.org/10.1016/j.engstruct.2016.11.032.

Consiglio Nazionale delle Ricerche, 2014. CNR-DT 212/2013, Istruzioni per la Valutazione Affidabilistica della Sicurezza Sismica di Edifici Esistenti, Roma. Online: www.cnr.it/documenti/norme/IstruzioniCNR_DT212_2013.pdf (10 March 2019)

De Stefano, M., Cristofaro M. T. 2018. 3.2 Final evaluation of the seismic response of the Galleria dell'Accademia complex in Florence and evaluation levels LV1, LV2 and LV3. In: The evaluation of seismic risk in the complex of the Galleria dell'Accademia of Florence. An experimental application of the MiBACT Guidelines for the evaluation and reduction of seismic risk of cultural heritage (2009-2013), G. Giorgianni ed., Altralinea ISBN 9788894869262.
Díaz Vilariño, L., Boguslawski, P., Azenha, M., Mahdjoubi, L., Lourenço, P. B., Arias, P. 2017. From LiDAR data towards HBIM for energy analysis. In: Heritage Building Information Modelling Arayici, Y., Counsell, J., Mahdjoubi, L., Nagy, G., Hawas, S. and Dewidar, K., eds.. Routledge, pp. 224-241. ISBN 9781138645684 .

D.M. 10/05/2001 Atto di indirizzo sui criteri tecnico-scientifici e sugli standard di funzionamento e sviluppo dei musei GU Serie Generale n.244 del 19-10-2001 - Suppl. Ordinario n. 238. Online:

https://www.beniculturali.it/mibac/multimedia/MiBAC/docume nts/1310746917330_DM10_5_01.pdf (10 March 2019)

D. M. 113/2018 Adozione dei livelli minimi uniformi di qualità per i musei e i luoghi della cultura di appartenenza pubblica e attivazione del Sistema museale nazionale. GU Serie Generale n.78 del 04-04-2018.

Online:

http://www.beniculturali.it/mibac/multimedia/MiBAC/documen ts/1523359335541_REGISTRATO_D.M._21_FEBBRAIO_201 8_REP._113.pdf (10 March 2019).

D.G.R. 29/052012 n. 24-3914 D.M. 10.5.2001. Standard di qualità nei musei piemontesi - Approvazione modalità e procedura di accreditamento e linee guida per la prosecuzione e lo sviluppo del progetto. Regione Piemonte BU26 28/06/2012 Online:

http://www.regione.piemonte.it/governo/bollettino/abbonati/201 2/26/attach/dgr_03914_620_29052012.pdf (10 March 2019)

Dore, C., Murphy, M., McCarthy, S., Brechin, F., Casidy, C., \& Dirix, E. 2015. Structural simulations and conservation analysis-historic building information model (HBIM). Int. Arch. Photogramm. Remote Sens. Spatial Inf. Sci. 40(5), 351.

doi.org/10.5194/isprsarchives-XL-5-W4-351-2015.

Filippi, M., Rota, M., 2010. Confidential Facility Report: a tool for quality evaluation and decision making in museums. In: 4th Int. Congress Science and Technology for the Safeguard of Cultural Heritage in the Mediterranean Basin, Ferrari A. cur. 391-395. ISBN 889668031X.

Gigliarelli, E., Calcerano, F., \& Cessari, L. 2017. Heritage Bim, numerical simulation and decision support systems: An integrated approach for historical buildings retrofit. Energy Procedia, 133, 135-144. doi.org/10.1016/j.egypro.2017.09.379.

Greco A., Lombardo G., Pantò B., Famà A., 2018. Seismic Vulnerability of Historical Masonry Aggregate Buildings in Oriental Sicily, International Journal of Architectural Heritage. doi.org/10.1080/15583058.2018.1553075.

Green, D., Mustaligh, R., 2009. Digital Technologies and the Management of Conservation Documentation, Andrew W. Mellon Foundation White paper. Online: http://mac.mellon.org/mac-

files/Mellon\%20Conservation\%20Survey.pdf (10 March 2019)

ICOM 2017. ICOM Code of ethics for museums Online: https://icom.museum/wp-content/uploads/2018/07/ICOM-codeEn-web.pdf (10 March 2019).

Joblot, L., Paviot, T., Deneux, D., \& Lamouri, S. 2017. Literature review of Building Information Modeling (BIM) 
intended for the purpose of renovation projects. IFACPapersOnLine, 50(1), 10518-10525.

doi.org/10.1016/j.ifacol.2017.08.1298.

Khodeir, L. M., Aly, D., Tarek, S. 2016. Integrating HBIM (Heritage Building Information Modeling) tools in the application of sustainable retrofitting of heritage buildings in Egypt. Procedia Environmental Sciences, 34, 258-270. doi.org/10.1016/j.proenv.2016.04.024.

Korumaz, M., Betti, M., Conti, A., Tucci, G., Bartoli, G., Bonora, V., Korumaz, A.G., Fiorini, L. 2017 An integrated Terrestrial Laser Scanner (TLS), Deviation Analysis (DA) and Finite Element (FE) approach for health assessment of historical structures. A minaret case study. Engineering Structures 2017; 153: $224-238$.

doi: 10.1016/j.engstruct.2017.10.026.

López, F.J.; Lerones, P.M.; Llamas, J.; Gómez-García-Bermejo, J.; Zalama, E. 2018. A Review of Heritage Building Information Modeling (H-BIM). Multimodal Technologies Interact., 2, 21. doi.org/10.3390/mti2020021.

Lucchi, E., 2018 Review of preventive conservation in museum buildings, Journal of Cultural Heritage 29 180-193. doi.org/10.1016/j.culher.2017.09.003.

Macher, H., Landes, T., Grussenmeyer, P., 2017. From Point Clouds to Building Information Models: 3D Semi-Automatic Reconstruction of Indoors of Existing Buildings Appl. Sci. 2017, 7, 1030. doi.org/10.3390/app7101030

Masiero, A.; Fissore, F.; Guarnieri, A.; Pirotti, F.; Visintini, D.; Vettore, A., 2018. Performance Evaluation of Two Indoor Mapping Systems: Low-Cost UWB-Aided Photogrammetry and Backpack Laser Scanning. Appl. Sci., 8, 416.

doi.org/10.3390/app8030416

Masiero, A., Tucci, G., Conti, A., Fiorini, L., Vettore, A., 2019. Initial evaluation of the potential of smartphone stereo-vision in museum visits. Int. Arch. Photogramm. Remote Sens. Spatial Inf. Sci., (forthcoming).

MIBAC 2008, Linee Guida per la valutazione e riduzione del rischio sismico del patrimonio culturale allineate alle nuove Norme tecniche per le costruzioni (D.M. 14 gennaio 2008). Online: https://www.beniculturali.it/mibac/export/MiBAC/sitoMiBAC/Contenuti/Avvisi/visualizza_asset.html_1141304737.ht $\mathrm{ml}$ (10 March 2019).

Pepper D. W., Kassab A. J., Divo E. A. 2014. An Introduction To Finite Element, Boundary Element, And Meshless Methods With Applications To Heat Transfer And Fluid Flow, ASME Press.

Pieraccini, M., Betti, M., Forcellini, D., Devis, D., Papi, F., Bartoli, G., Facchini, L., Corazzi, R., Kovacevic, C.V. 2017. Radar detection of pedestrian-induced vibrations of Michelangelo's David. Plos ONE, 12(4), e0174480. doi.org/10.1371/journal.pone.0174480.

Pocobelli, D. P., Boehm, J., Bryan, P., Still, J., Grau-Bové, J., 2018. BIM for heritage science: a review. Heritage Science 6:30. doi.org/10.1186/s40494-018-0191-4.
Rodrigues, F., Teixeira, J., Matos, R., \& Rodrigues, H. 2019. Development of a Web Application for Historical Building Management through BIM Technology. Advances in Civil Engineering, vol. 2019, Art ID 9872736 doi.org/10.1155/2019/9872736.

Tucci G., Conti A., Fiorini L. 2016. Realizzazione ed impiego del rilievo 3D, in: Il Ratto delle Sabine e il suo restauro. Giambologna, Bracci S., Brunori L. eds., Città di Castello, sillabe, 85-86 ISBN 978-88-8347-805-5.

Tucci, G., Bonora, V., Conti, A., Fiorini, L. 2017. 1.5 The gallery measured. In: The evaluation of seismic risk in the complex of the Galleria dell'Accademia of Florence. An experimental application of the MiBACT Guidelines for the evaluation and reduction of seismic risk of cultural heritage (2009-2013), G. Giorgianni ed., Altralinea ISBN 9788894869262 .

Tucci, G., Conti, A., Fiorini, L. 2018. Geomatics for structural assessment and surface diagnostic of $\mathrm{CH}$. Procedia Structural Integrity, 11, 2-11 doi.org/10.1016/j.prostr.2018.11.002.

Turco, M. L., Calvano, M., Giovannini, E. C. 2019. Data modeling for museum collections. Int. Arch. Photogramm. Remote Sens. Spatial Inf. Sci., XLII-2/W9, 433-440. doi.org/10.5194/isprs-archives-XLII-2-W9-433-2019.

UKRG 2015 United Kingdom Registars' Group. Standard Facilities Report. 2015

Online: https://www.ukregistrarsgroup.org/wp-

content/uploads/2015/12/UKRG_facilities_report.pdf $\quad(10$ March 2019).

Wang, Q., Guo, J., Kim, M., 2019. An Application Oriented Scan-to-BIM Framework. Remote sensing. doi.org/10.3390/rs11030365.

Yang, X., Koehl, M., Grussenmeyer, P. 2018. Mesh-to-BIM: from segmented mesh elements to BIM model with limited parameters. Int. Arch. Photogramm. Remote Sens. Spatial Inf. Sci., XLII-2, 1213-1218. doi.org/10.5194/isprs-archives-XLII2-1213-2018 